\title{
Perancangan Alat Ukur Pergeseran Tanah Skala Laboratorium
}

\author{
Tri Siswandi Syahputra ${ }^{1}$, Heru Asyubi ${ }^{2}$, Mahardika Yoga Darmawan ${ }^{3}$ \\ Program Studi Fisika Institut Teknologi Sumatera, Lampung Selatan \\ Jalan Terusan Ryacudu, Way Hui, Kecamatan Jati Agung, Lampung Selatan 35365 \\ ${ }^{1}$ trisiswandiefi.itera.ac.id \\ ${ }^{3}$ mahardika.yoga@fi.itera.ac.id
}

Intisari - Peristiwa tanah longsor merupakan salah satu bencana alam yang sering terjadi di beberapa wilayah Indonesia. Peristiwa ini terjadi dengan durasi yang cepat sehingga sering kali menimbulkan kerugian material. Untuk meminimalisasikan kerugian tersebut, perlu dilakukan metode pendeteksian fisis kejadian longsor dengan menggunakan sensor untuk mengukur pergeseran tanah. Pada penelitian sensor pergeseran tanah yang digunakan adalah potensiometer dan linear variable differensial transduser geser (LVDT) berbiaya rendah. Selain itu data fisis tambahan lainnya yang digunakan adalah sensor kelembabam tanah dan kemiringan tanah. Sistem sensor diujicoba pada skala laboratorium untuk mengetahui pengaruhnya terhadap pergeseran tanah. Nilai potensiometer geser dan LVDT dapat mengukur pegeseran tanah $0.5 \mathrm{~mm}$ dan menghasilkan grafik yang berpola linear dengan nilai galat rata rata $2 \%$. Sistem tersebut juga disambungkan ke sistem IoT dengan jeda pengiriman data ke platform 15 detik.

Kata kunci - Pergeseran Tanah, LVDT, Potensiometer Geser, Monitoring.

Abstract - Landslide is one of the natural disasters that frequently occurs in several parts of Indonesia. This event often exists in rapid duration time which may cause material losses. In order to minimize these losses, a landslide detection method using a land displacement sensor is needed to be investigated. In this research, a potentiometer and low cost linear variable differential transducer (LVDT) are used as the land displacement sensor. In addition, sensors of soil moisture and soil slope are utilized to complete other additional physical data. A laboratory scale test is carried out on the sensors to determine its effect on soil displacement. The value of the shear potentiometer and LVDT can measure a soil shift of $0.5 \mathrm{~mm}$ and result a graph of linear pattern with an average error value of $2 \%$. The system is also connected to the IoT system with a 15 seconds delayed in sending data to the platform.

Keywords - Soil Displacement, LVDT, Shift Potentiometer, Monitoring

\section{PENDAHULUAN}

Bencana tanah longsor secara alami tidak dapat dihindari, namun kerugian yang ditimbulkannya, seperti jatuhnya korban jiwa dapat diminimalisir dengan cara membangun sistem pendeteksian dini tanah longsor. Sistem pendeteksian dini tanah longsor merupakan sistem yang disusun untuk mendeteksi adanya pergerakan tanah yang disebabkan oleh berbagai indikator seperti curah hujan yang tinggi, kondisi geologi tanah dan faktor lainnya [1]. Secara umum, sistem pendeteksi dini tanah longsor yang telah dikembangkan dapat diklasifikasikan menjadi 2 bagian yaitu alarm system, warning system dan forecasting system [2]. Kedua sistem tersebut diklasifikasikan berdasarkan analisis data dan sistem deteksi yang dikembangkan. Selain itu, sistem tersebut berkerja dengan konfigurasi berbagai sensor seperti soil moisture, extensometer, acoustic, rain gauge, geophone, dan sensor radar [3].

Beragam teknik deteksi dini tanah longsor telah banyak dikembangkan dengan dengan menggunakan sensor sederhana dengan berbagai konfigurasi. Salah satu teknologi deteksi dini longsor yang cukup umum digunakan adalah menggunakan exstensometer dan sensor ultrasonik. Sensor tersebut dapat membaca pergeseran tanah dalam skala $1 \mathrm{~cm}$ [4]. Metode selanjutnya dengan menggunakan sensor variabel resistor yang dapat mengukur perubahan jarak sebesar $1 \mathrm{~cm}$. Pengembangan metode baru dengan menggunakan sensor accelometer dilaporkan juga dapat mendeteksi perubahan sampai 1 mm dengan pergeseran maksimum $250 \mathrm{~mm}$ [5-7]. Dalam penelitian ini akan dirancang suatu alat ukur pergeseran tanah berbiaya 
rendah dengan menggunakan sensor potensiometer geser dan sensor linear variable differensial transduser (LVDT) yang terhubung dengan internet of things (IoT). Sensor kelembaban tanah dan kemiringan juga dipasang sekaligus dengan harapan dapat membaca secara konprehensif besaran fisis dalam peristiwa longsor.

\section{TINJAUAN PUSTAKA}

\section{A. Pergerakan Tanah}

Peristiwa Longsor yang diawali oleh pergerakan tanah merupakan peristiwa geologi yang terjadi karena pergerakan massa tanah atau batuan penyusun lereng ke arah kaki lereng akibat dari terganggunya kestabilan tanah atau batuan penyusun lereng tersebut. jika massa yang bergerak ini didominasi oleh massa tanah dan gerakannya melalui bidang miring atau lengkung, maka proses pergerakan tersebut dinamakan longsoran tanah.

Pergerakan tanah dapat diklasifikasikan menjadi beberapa tipe (Gambar 1) yaitu: jatuhan (falls), aliran translasi (flows), longsoran blok (slides), Longsoran Rotasi (slump) dan amblesan (creep). Ada dua faktor penting didalam menentukan tipe-tipe pergerakan tanah, yaitu: kecepatan gerakannya dan kandungan air di dalam materi yang mengalami gerakan tanah [1].

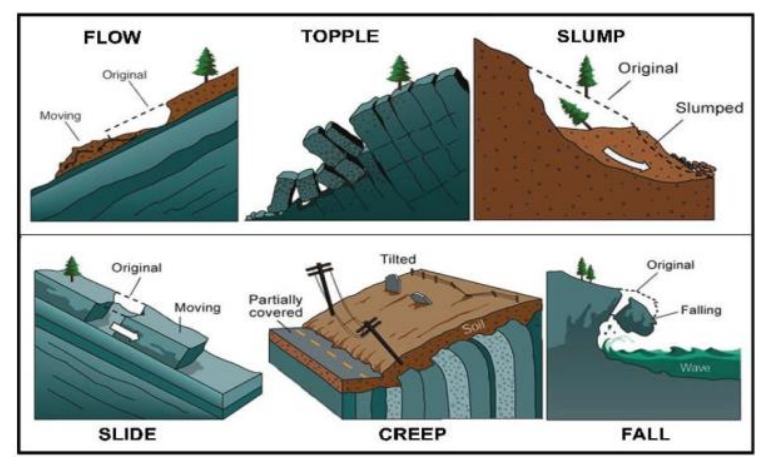

Gbr.1 Mekanisme terjadinya longsor [1]

Terjadinya longsor selain dipengaruhi oleh aktivitas internal lereng tersebut, seringkali dipicu oleh hal lain yaitu ; hujan, getaran dan aktivitas manusia.

Pemicu ini dapat berperan dalam mempercepat peningkatan gaya penggerak/ peluncur/driving force, mempercepat pengurangan gaya penahan gerakan/resisting force, ataupun sekaligus mengakibat keduanya. Hujan merupakan pemicu yang bersifat alamiah; getaran-getaran dapat bersifat alamiah (misalnya gempa bumi) ataupun non alamiah (misalnya ledakan atau getaran lalu lintas). Aktivitas manusia seperti penggalian atau pemotongan pada lereng dan pembebanan merupakan pemicu yang bersifat non alamiah.

\section{B. Mikrokontroler}

Arduino Uno adalah papan mikrokontroler open-source berbasis mikrokontroler Microchip ATmega 328P dan dikembangkan oleh Arduino.cc. Papan ini dilengkapi dengan set pin input/output (I/O) digital dan analog yang dapat dihubungkan ke berbagai papan ekspansi (pelindung) dan sirkuit lainnya. Papan ini memiliki 14 pin I/O digital (enam mampu menghasilkan PWM), 6 pin $\mathrm{I} / \mathrm{O}$ analog, dan dapat diprogram dengan Arduino IDE (Lingkungan Pengembangan Terpadu), melalui kabel USB tipe B. Ini dapat diaktifkan oleh kabel USB atau baterai eksternal 9 volt, meskipun menerima tegangan antara 7 dan 20 volt. Selain itu Arduino UNO juga memiliki kapasitas sebesar 8 bit yang dapat membaca 16 karakter dalam bentuk biner, dan juga memiliki kapasitas penyipanan $32 \mathrm{~kb}$.

\section{Sensor LVDT}

Sensor LVDT adalah sensor linear yang berfungsi sebagai transducer elektromagnetik yang bisa mengkonversi gerak lurus pada suatu material menjadi sinyal listrik.

Sensor LVDT juga berfungsi untuk mengukur gerakan kecil mulai dari beberapa inci sampai seperjuta inci. Pada dasarnya, sensor LVDT terdiri dari dua buah kumparan sekunder, satu kumparan primer, dan inti bahan feromagnetik.

Semua kumparan tersebut dililit pada sebuah pipa, sedangkan inti diletakkan pada bagian tengah pipa tersebut seperti terlihat pada gambar 2 . 


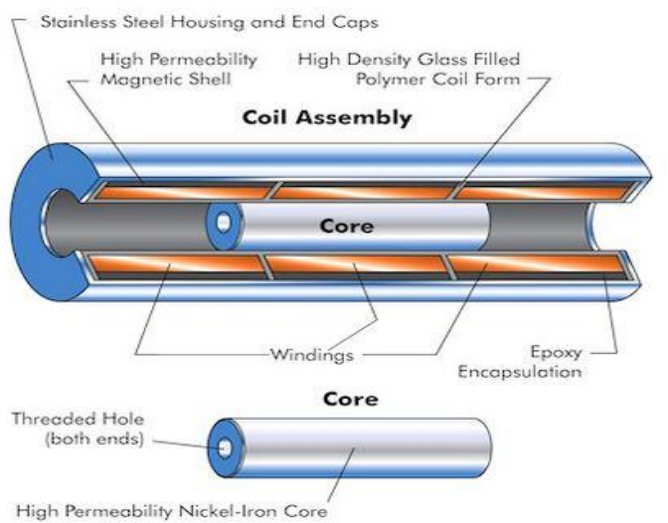

Gbr.2 Bentuk LVDT

\section{Potensiometer Geser}

Potensiometer geser merupakan salah satu jenis resistor variabel yaitu resistor yang dapat diubah nilai tahanannya. Salah satu jenis potensiometer adalah potensiometer geser, yaitu potensiometer yang nilai tahanannya dapat diubah dengan cara menggeser knop geser yang ada pada potensiometer tersebut. Skema komponen penyusun potensiometer geser ditunjukan pada gambar berikut :

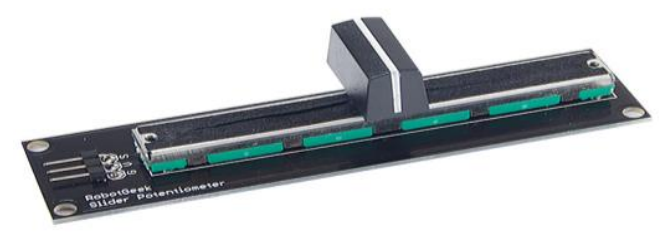

Gbr.3 Potensiometer Geser

\section{E. Sensor Soil Moisture}

Sensor ini terdiri dua probe untuk melewatkan arus melalui tanah, kemudian membaca nilai resistansinya untuk mendapatkan nilai tingkatan kelembaban. Semakin banyak air yang terkandung membuat tanah lebih mudah menghantarkan listrik (resistansi kecil), sedangkan tanah yang kering sangat sulit untuk menghantarkan listrik (resistansi besar). Sensor ini memiliki spesifikasi tegangan input sebesar $3.3 \mathrm{~V}$ atau $5 \mathrm{~V}$, tegangan output sebesar $0 \pm 4.2 \mathrm{~V}$, arus sebesar $35 \mathrm{~mA}$, dan memiliki value range ADC sebesar 1024 bit mulai dari $0 \pm 1023$ bit.

\section{$F$. Internet of Things (IoT)}

Internet of Things merupakan sebuah konsep yang dibentuk dengan tujuan memperluas konektivitas internet dan tersambung secara terus menerus. IoT sendiri mengacu pada benda yang teridentifikasi secara unik sebagai representasi fisik dalam struktur yang berbasis internet. Konsep IoT sendiri biasa digunakan untuk berbagi data dengan jarak yang jauh melalui internet, remote control, dan sebagainya, termasuk dalam merepresentasikan benda didunia nyata ke dunia maya [8]. Berikut skema secara umum pada sistem IoT.

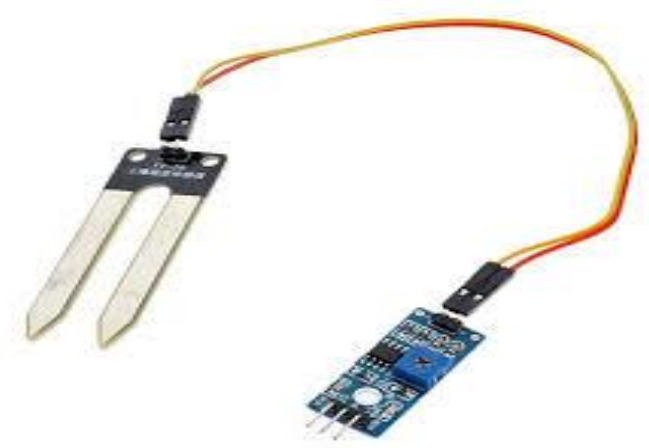

Gbr.4 Soil Moisture Sensor

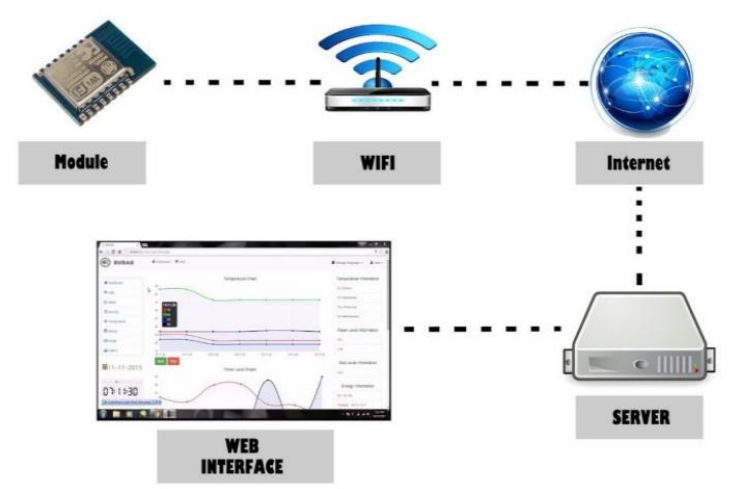

Gbr.5 Skema umun sistem IoT

\section{METODE PENELITIAN}

\section{A. Instrumen Penelitian}

Perancangan perangkat keras pada penelitian ini menggunakan menggunakan atmega 328, esp 01, potensiometer geser, LVDT berbiaya rendah, sensor gyroscope MPU6050, dan sensor soil moisture. Sensorsensor tersebut disusun sedemikian rupa kemudian diujicoba dengan menggunakan bak penampungan berisi tanah dan disetting seperti peristiwa hujan. Kemudian sistem dihubungkan dengan platform IoT Thingspeak sebagai penyimpan dan interface data. 
Sedangkan metode penelitian secara umum dijelaskan dalam bentuk diagram alir sebagai berikut :

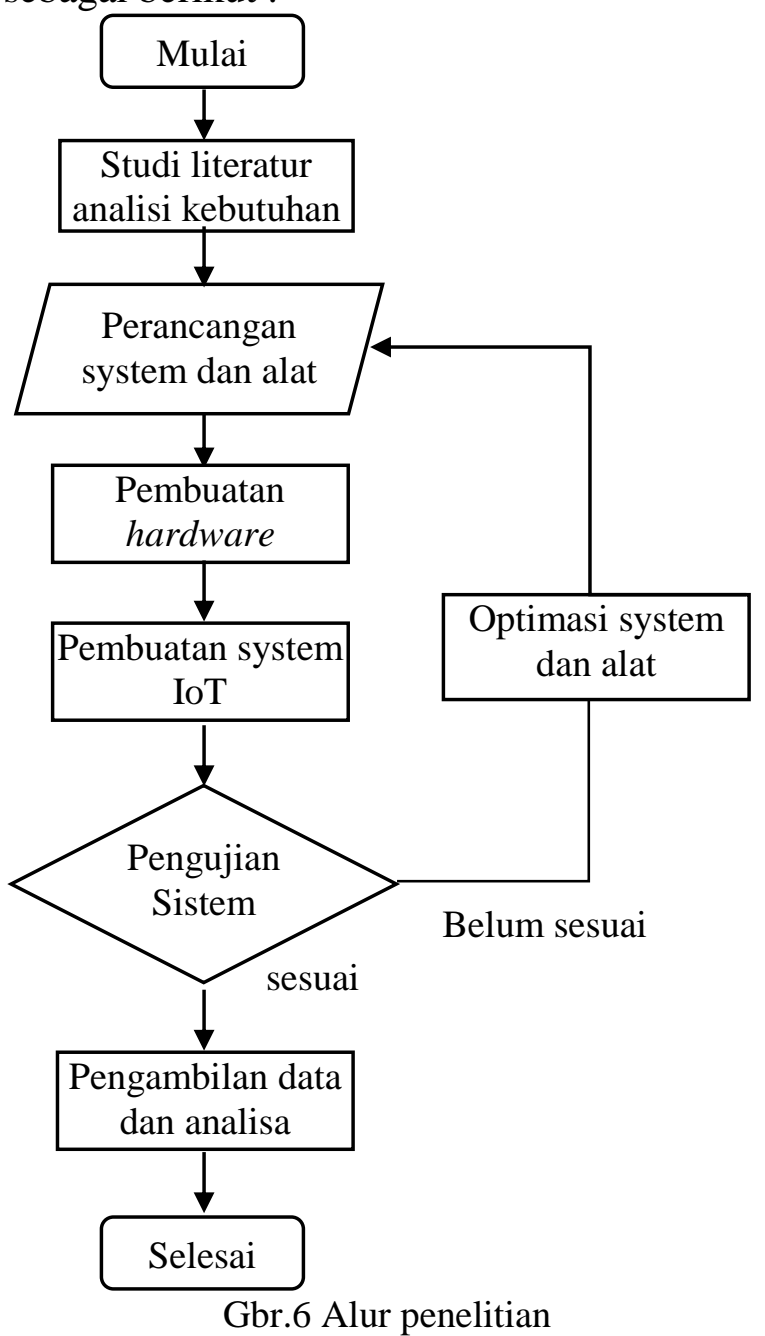

\section{B. Perancangan Sistem}

Perancangan alat ukur pergeseran tanah skala laboratorium dapat digambarkan pada skema berikut :

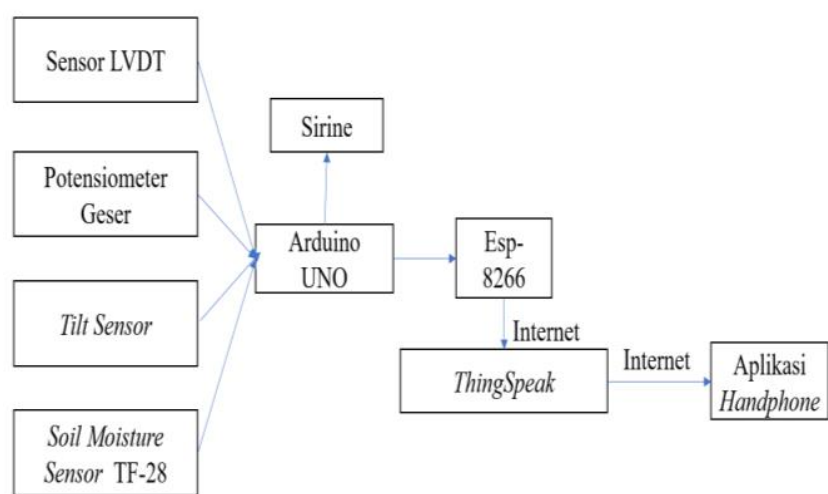

Gbr.7 Skema Alat Pendeteksi

Sedangkan skematik rangkaian keseluruhan digambarkan pada gambar berikut :

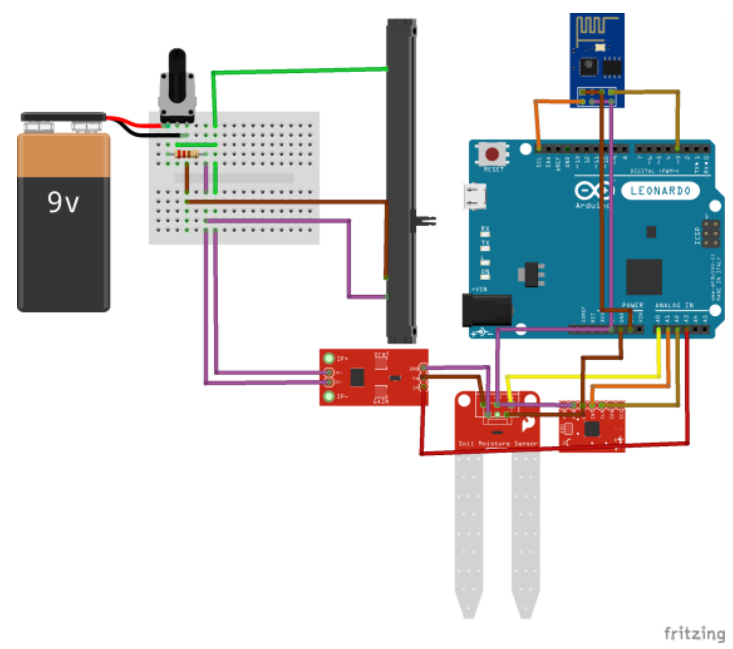

Gbr.8 Gambar skematik rangkaian

\section{HASIL DAN PEMBAHASAN}

\section{A. Pengujian Potensiometer Geser}

Potensiometer geser yang dibuat manual telah dilakukan pengujian dengan cara menggeser elektroda sejauh $2 \mathrm{~cm}$ dan menghasilkan luaran pada gambar berikut :

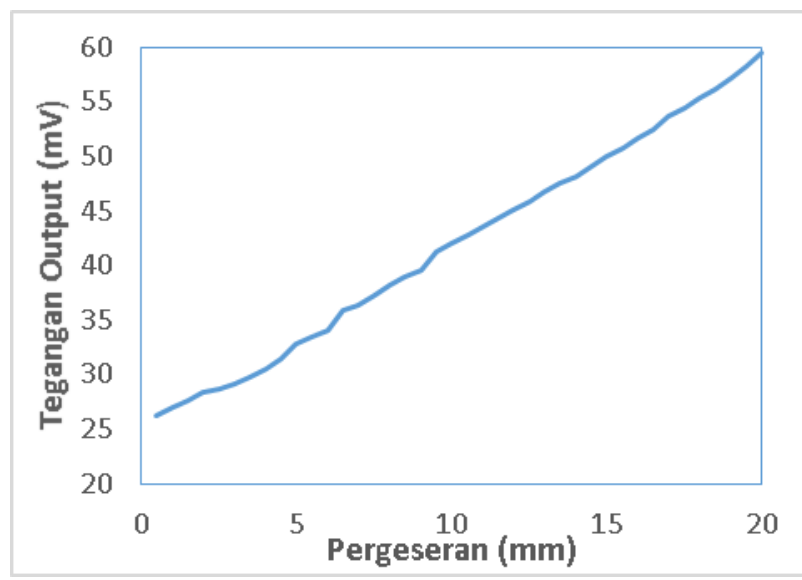

Gbr. 9 Hubungan pergeseran elektroda dengan tegangan keluaran

Dari gambar 9 terlihat bahwa hubungan antara pergeseran elektroda dalam potensiometer geser dengan tegangan output tegangan membentuk pola linear dimana tegangan awal $26.2 \mathrm{mV}$ dan tegangan pada jarak $2 \mathrm{~cm}$ bernilai $59.4 \mathrm{mV}$. Hal ini sesuai dengan teori bahwa semakin besar perubahan jarak semakin besar tegangan yang dihasilkan.

\section{B. Pengujian LVDT}

Selain pembuatan potensiometer geser, sensor LVDT juga dibuat secara manual untuk mengetahui pengaruh antara jumlah lilitan primer, sekunder dan diamter lilitan. 
Dari hasil pengujian sensor LVDT menghasilkan keluaran tegangan seperti pada gambar berikut :

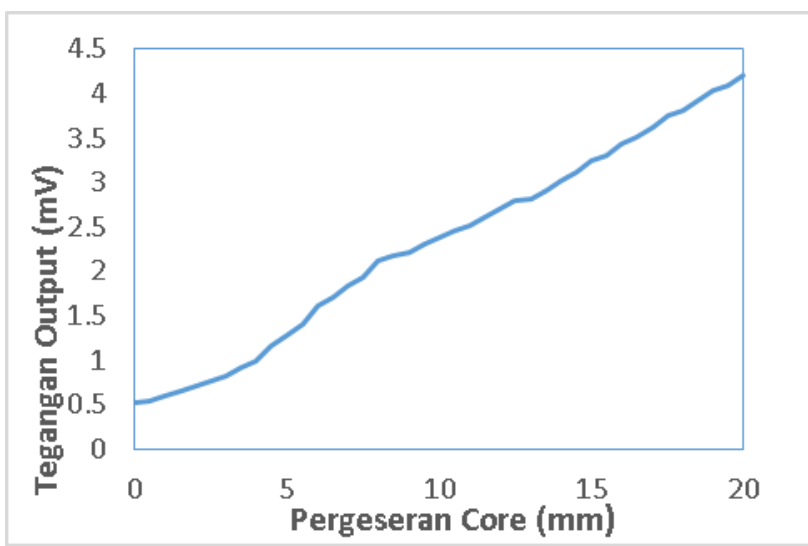

Gbr.10 Hubungan pergeseran core dengan tegangan keluran

Pada Gambar 10 dapat dilihat bahwa kurva pergeseran core dan output terlihat kelinearan. Data terkecil dari sensor adalah 0.52 dan data tegangan keluaran tertinggi adalah $4.21 \mathrm{mV}$. Pada saat pengujian sensor ini, jangka sorong digunakan untuk memastikan bahwa pergeseran yang dilakukan sudah sesuai dengan yang terukur [9-10].

\section{Pengujian Sensor Soil Moisture}

Untuk mengetahui kinerja sensor kelembaban tanah, pengujian dilakukan dengan meletakan sensor kelemban tanah kedalam tanah dengan berat 250 gram. Tanah tersebut disusun secara miring kemudian disiram air dengan volume $10 \mathrm{ml}$ dan kelipatannya hingga volume akhir $200 \mathrm{ml}$. hasilnya tegangan analog dari sensor dapat digambarkan sebagai berikut :

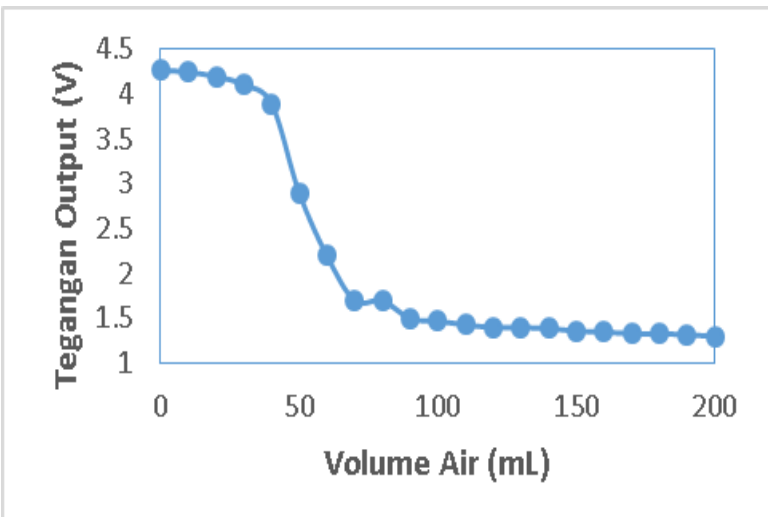

Gbr.11 Hubungan penambahan volume air dengan tegangan keluaran
Dari Gambar 11 diatas dapat terlihat bahwa pada saat volume air yang dikenakan diatas $50 \mathrm{~mL}$ terlihat tegangan yang dihasilkan semakin kecil yang menunjukan nilai kelembabannya tinggi, kemudian setelah $100 \mathrm{~mL}$ terlihat tegangan analognya tidak banyak berubah hal ini dikarenakan air sudah besifat jenuh.

\section{Pengujian Sensor Gyroscope}

Pengujian Gyroscope dilakukan untuk mendapatkan data variasi kemiringan sebagai berikut :

Tabel 1. Pengujian sensor gyroscope

\begin{tabular}{|c|c|c|c|}
\hline No. & Sudut & Arah X & Arah Y \\
\hline 1 & $\begin{array}{c}\mathrm{X}=0^{0} \\
\mathrm{Y}=0^{0}\end{array}$ & $0.15^{0}$ & $0.80^{\circ}$ \\
\hline 2 & $\begin{array}{c}\mathrm{X}=0^{0} \\
\mathrm{Y}=90^{0}\end{array}$ & $88.40^{\circ}$ & $2.64^{0}$ \\
\hline 3 & $\begin{array}{c}\mathrm{X}=90^{0} \\
\mathrm{Y}=0^{0}\end{array}$ & $1.88^{0}$ & $88.68^{0}$ \\
\hline
\end{tabular}

Dari tabel diatas dapat terlihat bahwa sensor dapat mendeteksi perubahan sudut yang baik meskipun ada perbedaan kecil antara sudut acuan dengan sudut yang dibaca.

\section{E. Pengujian Sistem Keseluruhan}

Dalam pengujian keseluruhan, sensor yang digunakan adalah sensor potensiometer geser, sensor soil moisture dan sensor kemiringan. Secara umum belum ada referensi yang menyebutkan secara pasti seberapa besar pergeseran tanah yang berpeluang untuk menjadikan longsor. Hal ini disebabkan karena secara umum lonsor juga dapat diakibatkan oleh curah hujan dan faktor lainnya. Maka dari itu, peneliti membuat sebuah tabel peluang terjadinya lonsor sebagai berikut :

Tabel 2. Pengujian system sensor keseluruhan

\begin{tabular}{|c|c|c|c|c|}
\hline No & $\begin{array}{l}\text { Kondisi } \\
\text { Tanah }\end{array}$ & $\begin{array}{l}\text { Kelembaban } \\
\text { Tanah }\end{array}$ & $\begin{array}{l}\text { Stat } \\
\text { us }\end{array}$ & Keterangan \\
\hline 1 & Diam & $<40 \%$ & $\begin{array}{l}\text { Ama } \\
\mathrm{n}\end{array}$ & Berhasil \\
\hline 2 & Diam & $>40 \%$ & $\begin{array}{l}\text { Awa } \\
\text { s }\end{array}$ & Berhasil \\
\hline 3 & $\begin{array}{l}\text { Bergerak }< \\
2 \mathrm{~cm}\end{array}$ & $<40 \%$ & $\begin{array}{l}\text { Awa } \\
\text { s }\end{array}$ & Berhasil \\
\hline 4 & $\begin{array}{l}\text { Bergerak < } \\
2 \mathrm{~cm}\end{array}$ & $>40 \%$ & $\begin{array}{l}\text { Bah } \\
\text { aya }\end{array}$ & Berhasil \\
\hline 5 & $\begin{array}{l}\text { Bergerak > } \\
2 \mathrm{~cm}\end{array}$ & $<40 \%$ & $\begin{array}{l}\text { Bah } \\
\text { aya }\end{array}$ & Berhasil \\
\hline 6 & $\begin{array}{l}\text { Bergerak > } \\
2 \mathrm{~cm}\end{array}$ & $>40 \%$ & $\begin{array}{l}\text { Bah } \\
\text { aya }\end{array}$ & Berhasil \\
\hline
\end{tabular}


Pada tabel 2 terlihat bahwa system bekerja dengan baik dengan acuan yang digunakan. Dalam pengujian ini system disetting untuk dapat mengukur pergeseran tanah sampai 2 cm sebagai indikator bahwa keadaan tanah belum berbahaya, jika system membaca terdapat pergeseran tanah lebih dari 2 meter maka system akan memberikan keterangan bahaya. Begitu juga dengan indikator kelembaban tanah.

\section{KESIMPULAN}

Telah dilakukan penelitian mengenai perancangan alat ukur pergeseran tanah skala laboratorium untuk dapat mendeteksi gejala awal tanah longsor. Berdasarkan data data yang didapat, masing masing sensor dapat bekerja dengan baik dengan tingkat galat rata rata yang cukup kecil sebesar $2 \%$. Kemudian sensor juga dapat terhubung baik dengan perangat IoT dengan platform Thinspeak.

\section{UCAPAN TERIMA KASIH}

Penulis mengucapkan ucapan terima kasih sebesar besarnya kepada ristekdikti yang telah memberikan bantuan pendanaan melalui skema penelitian dosen pemula tahun pelaksanaan 2020 .

\section{REFERENSI}

[1] H. C. Hardiyatmo, Tanah Longsor \& Erosi, Kejadian dan Penanganan, Yogyakarta: Gadjah Mada University Press 2012

[2] M. Stähli1, M. Sättele, et all "Monitoring and prediction in early warning systems for rapid mass movements" Nat. Hazards Earth Syst. Sci., 15, 905-917, 2015

[3] G. Gigli, F. Mugnai, et all "Design and implementation of a landslide early warning system" Engineering Geology 147-148, 2012

[4] N. L. D. R Ari Sandi, R. Wirawan, L. Mardiana, D.W Kurniawidi, I. W. Sudiarta "Rancang Bangun Sistem Pendeteksi Tanah Longsor Sederhana Berbasis Sensor Soil Moisture dan Sensor Ultrasonik, Prosiding SKF, 2016.
[5] Suraya, M.A. Novianta "Perancangan Sistem Pergeseran Tanah Menggunakan Sensor Draw Wire Berbasis Mikrokontroler Dengan Informasi Sms Gateway Prosiding SENATEK 2015.

[6] M. Jamil, J. Togubu "Implementasi Teknologi Wireless Sensor Network untuk monitoring Pergeseran tanah. Jurnal Protek Vol 03, 2016.

[7] Onny Octaviani "Sistem Peringatan Dini Bencana Longsor Menggunakan Sensor Accelerometer dan Sensor Kelembaban Tanah Berbasis Android" Jurnal of Information Technology an Computing Engineering Vol 02 No 02, 2018

[8] M. El Moulata,O. Debaucheb, et all, "Monitoring system using intenet of things for potential landslide"Procedia Computer Science 26-34, 2018

[9] J. Priyanto, H. Subagiyo, P. Madona " Sistem Instrumentasi dan Monitoring Pergeseran tanah

Menggunakan Sensor LVDT Berbasis Mikrokontroler" Prosiding Applied Busines and Enginering Conference, 2015.

[10] W. Jefriyanto, B.G Saka, et all "Development of LVDT (Linear Variable Differential Transformer) as land displacement sensor" Prosiding $4^{\text {th }}$ International Seminar on Sensors, Instrumentation, Measurement and Metrology, 2020. 